\title{
Renal medullary (pro)renin receptor contributes to angiotensin II-induced hypertension in rats via activation of the local renin-angiotensin system
}

\author{
Fei Wang ${ }^{1,2}$, Xiaohan Lu' ${ }^{1}$ Mi Liu', Yumei Feng ${ }^{3}$, Shu-Feng Zhou ${ }^{4}$ and Tianxin Yang ${ }^{1,2^{*}}$
}

\begin{abstract}
Background: (Pro)renin receptor (PRR) is a new component of the renin-angiotensin system and regulates renin activity in vitro. Within the kidney, PRR is highly expressed in the renal medulla where its expression is induced by angiotensin II infusion. The objective of the present study was to test a potential role of renal medullary PRR during angiotensin II-induced hypertension.

Methods: A rat Angll infusion model (100 ng/kg/min) combined with renal intramedullary infusion of PRO20, a specific inhibitor of PRR, was builded. And the intravenous PRO20 infusion serve as control. Mean arterial pressure was recorded by radiotelemetry for one week. Further anaylsis of kidney injury, inflammation, biochemical indices and protein localization were perrformed in vivo or in vitro.

Results: Radiotelemetry demonstrated that Angll infusion elevated the mean arteria pressure from $108 \pm 5.8$ to $164.7 \pm 6.2 \mathrm{mmHg}$. Mean arterial pressure decreased to $128.6 \pm 5.8 \mathrm{mmHg}(P<0.05)$ after intramedullary infusion of PRO20, but was only modestly affected by intravenous PRO20 infusion. Indices of kidney injury, including proteinuria, glomerulosclerosis, and interstitial fibrosis, inflammation, and increased renal medullary and urinary renin activity following angiotensin II infusion were all remarkably attenuated by intramedullary PRO20 infusion. Following one week of angiotensin II infusion, increased PRR immunoreactivity was found in vascular smooth muscle cells. In cultured rat vascular smooth muscle cells, angiotensin II induced parallel increases in soluble PRR and renin activity, and the latter was significantly reduced by PRO20.
\end{abstract}

Conclusion: Renal medullary PRR mediates angiotensin II-induced hypertension, likely by amplifying the local renin response.

Keywords: Angiotensin II, PRO20, (Pro)renin receptor, Renin activity, Vascular smooth muscle cells

\section{Background}

The renin-angiotensin system (RAS) is one of the most important regulatory systems for the control of extracellular volume and blood pressure (BP). Over-activation of the RAS plays an essential role in the pathogenesis of hypertension as evidenced by the wide use of

\footnotetext{
* Correspondence: Yangtxin@mail.sysu.edu.cn

${ }^{1}$ Institute of Hypertension, Sun Yat-sen University School of Medicine, \#74 Zhongshan 2nd Road, Science and Technology Building, 6th Floor,

Guangzhou 510080, P. R. China

${ }^{2}$ Internal Medicine, University of Utah and Veterans Affairs Medical Center,

Salt Lake City, UT, USA

Full list of author information is available at the end of the article
}

angiotensin-converting enzyme (ACE) inhibitors and AT1-receptor antagonists for the management of human hypertension [1-3]. In humans and animals, activation of the RAS due to renal artery stenosis leads to profound hypertension and cardiovascular morbidity [4]. Angiotensin II (AngII), the major effector hormone of the RAS, when given at a pressor dose, readily induces hypertension [5]. However, despite intensive investigation, the mechanism of AngII-induced hypertension is still incompletely understood. Although diverse mechanisms have been proposed, increasing evidence suggests involvement of the local RAS found in a variety of 
tissues, including the brain, heart, adrenal gland, vasculature, and kidney $[6,7]$. Over the past decade, there has been a paradigm change in our understanding of the potential role of the local versus systemic RAS in the pathogenesis of hypertension. In particular, mounting evidence is available to support an essential role of the intrarenal RAS in AngII-induced hypertension.

(Pro)renin receptor (PRR) was cloned as a specific receptor for prorenin and renin by Nguyen et al. in 2002 [8]. It is a 350-amino-acid protein containing a single transmembrane domain [9]. A soluble form of PRR (sPRR), that is, the N-terminal domain fragment, is generated by intracellular cleavage by furin and secreted in plasma [10]. The carboxyterminal tail has previously been purified from chromaffin granules as an $8-9-\mathrm{kDa}$ accessory protein (M8-9) of the vacuolar-type $\mathrm{H}$ ${ }^{+}$-ATPase and designated ATP6AP2 [11]. In vitro evidence demonstrates that prorenin bound to PRR has increased catalytic activity, thus mediating local AngII formation $[8,12]$. In light of its ubiquitous expression in a variety of tissues, PRR is postulated to function as a regulator of tissue renin activity [13]. However, there is no convincing in vivo evidence to prove the reninregulatory function of PRR. Apart from prorenin or renin activation, activation of PRR by (pro)renin stimulates a variety of signal transduction pathways such as mitogen-activated protein kinase [14] and Wnt- $\beta$ catenin pathways [15], independent of AngII [14, 15]. Within the kidney, high levels of PRR immunoreactivity have been detected in intercalated cells of the collecting duct $(C D)[16,17]$ as well as vascular smooth muscle cells (VSMC) [8]. Previous studies from us and others have shown that PRR expression in the kidney, particularly in the renal medulla, increases during AngIIinduced hypertension, dependent of the COX-2/EP4 pathway $[16,18-20]$. The present study tested the functional role of renal medullary PRR during AngII-induced hypertension.

\section{Methods}

\section{Rat experiments}

Male Sprague-Dawley rats (220-250 g, Charles River Laboratories, Wilmington, MA, USA) were cage-housed and maintained in a temperature-controlled room with a 12:12-h light-dark cycle, with free access to tap water and standard rat chow for 14 days. The animal protocols were approved by the Animal Care and Use Committees at Sun Yat-sen University and University of Utah. The rats underwent uninephrectomy with or without bilateral adrenalectomy and were instrumented with radiotelemetric devices. After one week's recovery from the surgery, a second surgery was performed to place a subcutaneous osmotic mini-pump delivering vehicle or AngII at $100 \mathrm{ng} / \mathrm{kg} / \mathrm{min}$. In this surgery, the kidney was exposed from the flank region and a catheter was placed in the renal medulla, approximately $4.0 \mathrm{~mm}$ underneath the surface, and secured using Vetbond glue; the other end of the catheter was connected to an osmotic minipump delivering vehicle or PRO20 at $120 \mu \mathrm{g} / \mathrm{kg} / \mathrm{d}$. A separate group of rats received intravenous infusion of $\mathrm{PRO} 20$ via the jugular vein and served as a control. Adrenalectomized rats were given dexamethasone at $1 \mathrm{mg} /$ $\mathrm{ml}$ in their drinking water starting 2 days prior to adrenalectomy until the end of the experiment. The radiotelemetric device was implanted via catheterization of the carotid artery and was turned on for $4 \mathrm{~h}$ per day from 5:00 p.m. to 9:00 p.m. The data from the rats with incorrectly positioned intramedullary infusion catheters detected at sacrifice were excluded from the final analysis.

\section{Biochemical analysis of renin}

Renin activity in plasma, urine, tissue homogenates, and cell culture medium was determined under the native condition by measurement of AngI generation using enzyme-linked immunosorbent assay (ELISA). Aldosterone concentrations in plasma, urine, and cell culture medium were measured using a commercial ELISA kit (Cat\#:10004377, Cayman Chemical, Ann Arbor, Michigan, USA).

\section{Enzyme immunoassay}

To detect urinary or medium prorenin/renin, sPRR, we used the following commercially available enzyme immunoassay kits according to the manufacturer's instructions: prorenin/renin (Molecular Innovations, Novi, MI, USA) and sPRR (IBL, Toronto, Canada).

\section{Renal histology}

Under anesthesia, kidneys were harvested and fixed with $10 \%$ paraformaldehyde. The tissues were subsequently embedded in paraffin and $4-\mu \mathrm{m}$ sections were cut and stained with periodic acid-Schiff. Renal pathologies including glomerulosclerosis and interstitial fibrosis were scored on a 1-4 scale as previously described [21] (the higher the number, the more severe the injury).

\section{Quantitative reverse transcriptase polymerase chain reaction}

For Quantitative reverse transcription polymerase chain reaction (qRT-PCR), total RNA isolation and reverse transcription were performed as previously described [22]. Oligonucleotides were designed using Primer3 software (available at http://bioinfo.ut.ee/primer3-0.4.0/). Primers for TNF- $\alpha$ were $5^{\prime}$ - CCACGTCGTAGCAAACC ACCAAG-3' (sense) and 5' - CAGGTACATGGGCTCA TACC-3' (antisense); primers for IL-18 were $5^{\prime}$-TGGAGACTTGGAATCAGACC-3' (sense) and 5'-GGCAAGCTAGAAAGTGTCCT-3' (antisense); primers for GAPDH 
were 5' -GTCTTCACTACCATGGAGAAGG-3' (sense) and 5'-TCATGGATGACCTTGGCCAG-3' (antisense).

\section{Immunofluorescence staining}

The tissues were fixed in $10 \%$ neutral buffered formalin for $24 \mathrm{~h}$ and then embedded in paraffin. After deparaffinization, thin sections $(4 \mu \mathrm{m})$ were processed for double-labeling with immunofluorescence. The slides were blocked in $1 \%$ bovine serum albumin for $1 \mathrm{~h}$ and were then incubated with primary antibody at $4{ }^{\circ} \mathrm{C}$ overnight. After washing off the primary antibody, sections were incubated for $1 \mathrm{~h}$ at room temperature with Donkey anti-goat-IgG- fluorescein isothiocyanate (1:75, sc-2024, Santa Cruz Biotechnology, Santa Cruz, CA, USA) or donkey anti-rabbit IgGtetramethylrhodamine (1:100, A31572, Life Technologies, Grand Island, NY, USA). Rabbit anti-PRR antibody was raised against residues $335-350$ in the $C$ terminus (Cat\#: ab40790, Abcam, Cambridge, MA, USA). Mouse anti- $\alpha-$ smooth muscle actin ( $\alpha$-SMA) antibody was purchased from Sigma (Cat\#: F3777, Sigma, St Louis, MO, USA).

\section{Cell culture}

Rat aorta smooth muscle cell line (VSMC) was purchased from ATCC, Manassas, VA, USA (Cat\# CRL-2018) and
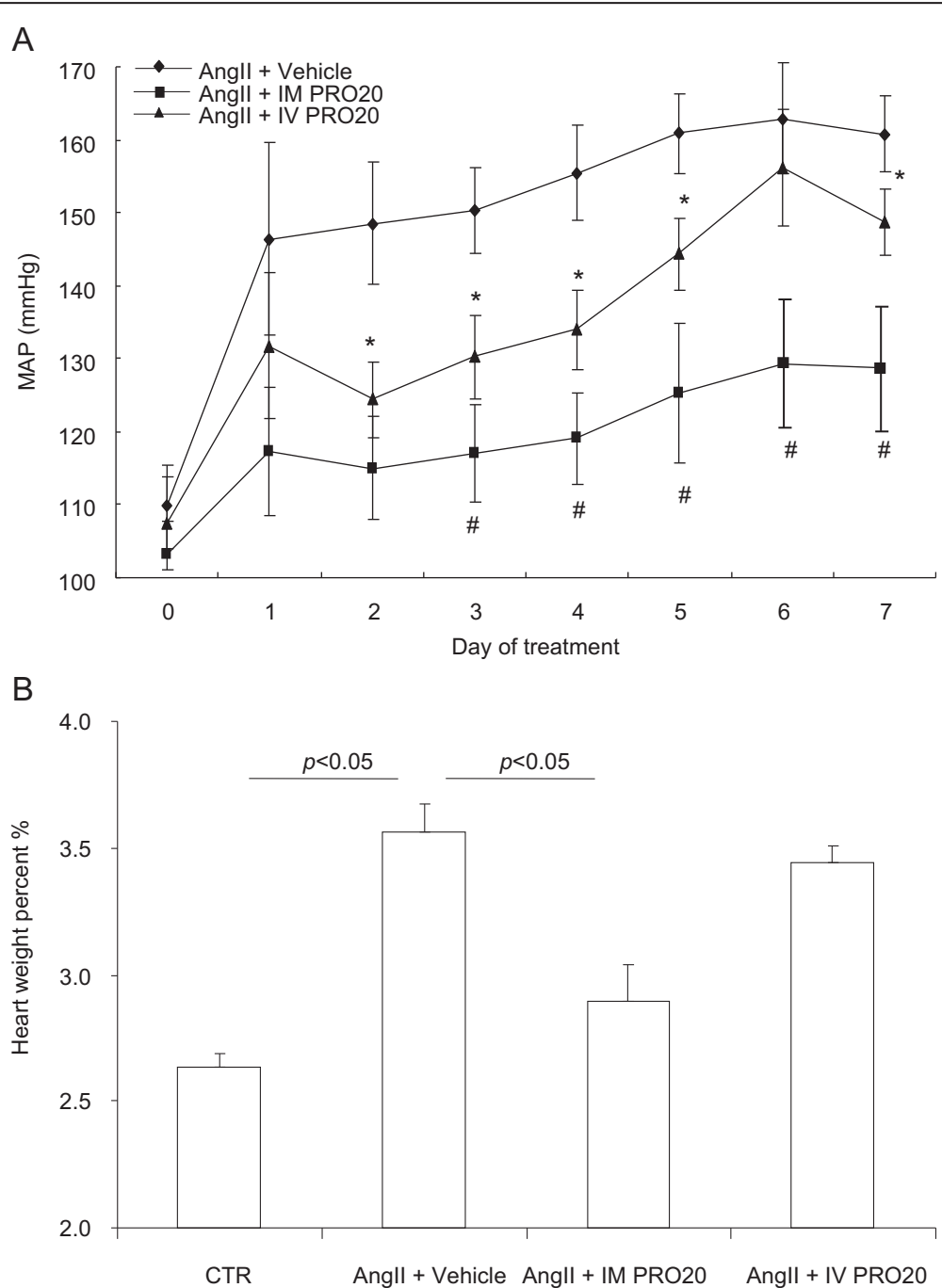

Fig. 1 Effect of intramedullary (pro)renin receptor (PRR) inhibition on angiotensin II (Ang/l)-induced hypertension in rats. Uninephrectomized male Sprague-Dawley rats were divided into the following three groups: (1) Angll, (2) Angll + intramedullary PRO20 infusion (IM PRO20), and (3) Angll + intravenous PRO20 infusion (IV PRO20). Angll was subcutaneously infused at $100 \mathrm{ng} / \mathrm{kg} / \mathrm{min}$ via an osmotic mini-pump. IM PRO20 (PRO20 at 120 $\mu \mathrm{g} / \mathrm{kg} / \mathrm{d}$ ) was performed via a catheter chronically implanted in the renal medulla. To control the spillover, IV PRO (PRO20 at $120 \mu \mathrm{gg} / \mathrm{kg} / \mathrm{d}$ ) was performed via catheterization of the jugular vein. Telemetry was performed to monitor mean arterial pressure (MAP) and it was turned on $4 \mathrm{~h}$ per day from 5:00 p.m. to 9:00 p.m. for 7 days. a Radiotelemetry monitoring of MAP. ${ }^{\#} P<0.01$ versus intravenous PRO20; ${ }^{*} P<0.05$ versus Angll alone. b Cardiac hypertrophy. Heart weight is expressed as percentage of body weight. Control (CTR), N=6; Angll + Vehicle, N=9; Angll + IM PRO20, N $=8$; Angll + IV PRO20, $\mathrm{N}=6$. Data are mean \pm standard error 
grown in a six-well plate. After the cell monolayers reached $95 \%$ confluence, the VSMCs were pretreated with PRO20 $(1.5 \mu \mathrm{M})$ for $1 \mathrm{~h}$, followed by AngII treatment at $100 \mathrm{nM}$ for $24 \mathrm{~h}$. After the treatment, the medium was collected for enzyme assays or renin assays.

\section{Statistical analysis}

Data is summarized as means \pm standard error (SE). All data points were included in the statistical analyses. Sample sizes were determined on the basis of similar previous studies or pilot experiments. Statistical analysis for animal and cell cultures experiments was performed using analysis of variance with the Bonferroni test for multiple comparisons or by paired or unpaired Student's $t$-test for two comparisons. A $P$-value below 0.05 was considered statistically significant.

\section{Results}

Pharmacological investigation of renal medullary function of PRR

PRO20 is a newly developed 21-amino-acid PRR decoy peptide that interrupts the binding of prorenin to PRR with high potency and specificity [23]. To probe the functional role of renal medullary PRR, we employed an intramedullary infusion technique that allows sitespecific delivery of an agent to the renal medulla [24]. To this end, a catheter was chronically implanted in the renal medulla of nephrectomized rats to achieve sitespecific delivery of PRO20, and intravenous infusion of this peptide via the jugular vein served as a control for spillover. Radiotelemetry was used to monitor daily mean arterial pressure (MAP). One-week AngII infusion induced immediate and sustained increases in MAP, from $108 \pm 5.8$ (day 0) to $164.7 \pm 6.2 \mathrm{mmHg}$ (day 7) (Fig. 1a). Intramedullary PRO20 infusion (IM PRO20) remarkably attenuated AngII-induced hypertension and lowered the MAP to $128.6 \pm 5.8 \mathrm{mmHg}$. However, intravenous PRO20 infusion (IV PRO20) was much less effective than IM PRO20 in lowering MAP (Fig. 1a). Consistent with the BP data, AngII-induced cardiac hypertrophy was blunted by IM PRO20 but not IV PRO20 (Fig. 1b).

Following AngII infusion, the uninephrectomized rats developed severe kidney injury as evidenced by increased proteinuria (Fig. 2a) and renal histological changes, including glomerulosclerosis and interstitial fibrosis
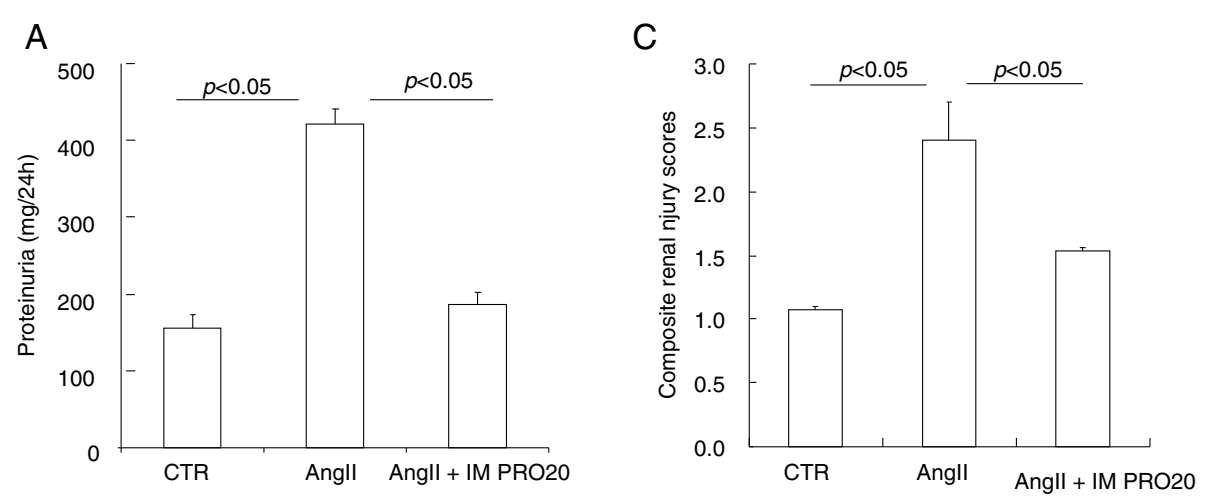

B
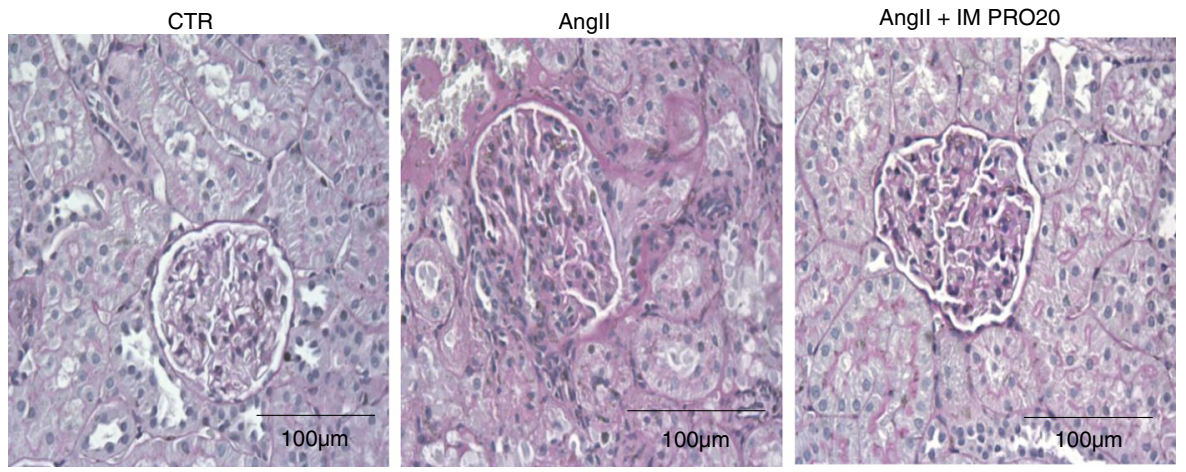

Fig. 2 Effect of intramedullary (pro)renin receptor (PRR) inhibition on angiotensin II (Angll)-induced kidney injury in rats. a Measurement of urinary protein excretion using Coomassie blue. $\mathbf{b}$ Representative micrographs of periodic acid-Schiff staining of kidney sections. c Renal injury scores from semi-quantitative analysis of renal pathologies. $\mathrm{N}=6-14$ per group. Data are mean \pm standard error. CTR control, IM PRO20 intramedullary PRO20 infusion, IV PRO20 intravenous PRO20 infusion 
(Fig. 2b, c). These indices of kidney injury were all attenuated by IM PRO20 (Fig. 2a-c). An inflammatory response is a well known important feature of AngIIinduced hypertension $[25,26]$. Therefore, we examined renal expression of inflammatory markers such as TNF$\alpha$ and IL-18 using qRT-PCR. Both cytokines were elevated by AngII infusion and were blunted by IM PRO (Fig. 3a, b). PRO20 treatment via intramedullary or intravenous infusion was not associated with any noticeable toxicity.

AngII infusion induces a local renin response in the renal medulla but suppresses systemic renin activity $[16$, 18, 27-29]. We hypothesized that PRR may be required to enhance the renal medullary renin response to AngII. As expected, following AngII infusion, renin activity was suppressed in plasma and the renal cortex but enhanced in the inner medulla and urine, and the latter response was blunted by IM PRO20 (Fig. 4a-d). ELISA showed that prorenin/renin content in the inner medulla was elevated by AngII infusion but was unaffected by IM PRO20 (Fig. 5a) and the same result was obtained by qRT-PCR of renin mRNA (Fig.5b), supporting the concept that PRR primarily regulates local renin activity but not renin expression. Of note, the ELISA kit was unable to differentiate between prorenin and renin.

\section{Regulation and function of vascular PRR}

Immunostaining revealed the strongest signal of PRR in the vascular smooth muscle in the kidney (Fig. 6a). This signal was specific because it was completely eliminated by the immunizing peptide (Fig. 6a). The vascular labeling of PRR appeared weaker in the heart as compared to that in the kidney (Fig. 6a). AngII infusion enhanced the vascular labeling of PRR in the kidney (Fig. 6b). PRR
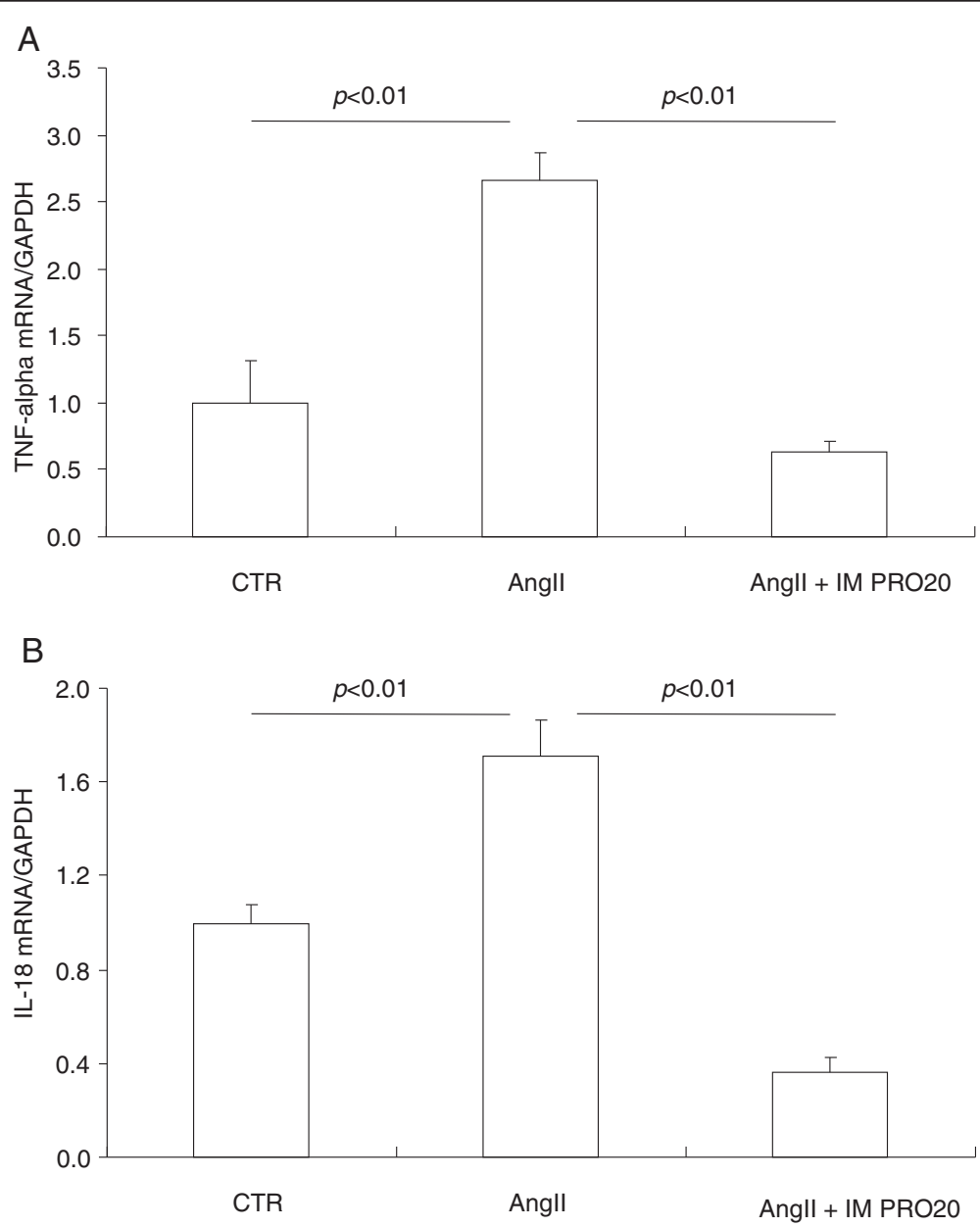

Fig. 3 Effect of intramedullary (pro)renin receptor (PRR) inhibition on renal inner medullary expression of cytokines during angiotensin II (AngII)induced hypertension in rats. a, b The expression of tumor necrosis factor alpha (TNF- $a$ ) and interleukin 18 (IL-18) in the inner medulla of control (CTR), Angll, and Angll + intramedullary PRO20-infused (Angll + IM RPO20) rats was determined by quantitative reverse transcriptase polymerase chain reaction, which is normalized by glyceraldehyde 3-phosphate dehydrogenase (GAPDH). N $=6$ per group. Data are mean \pm standard error 


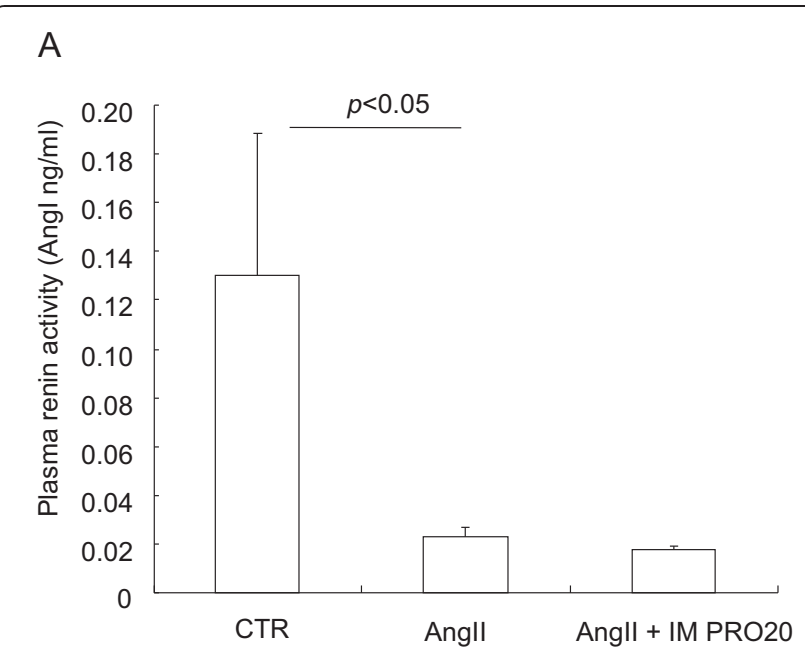

$\mathrm{B}$
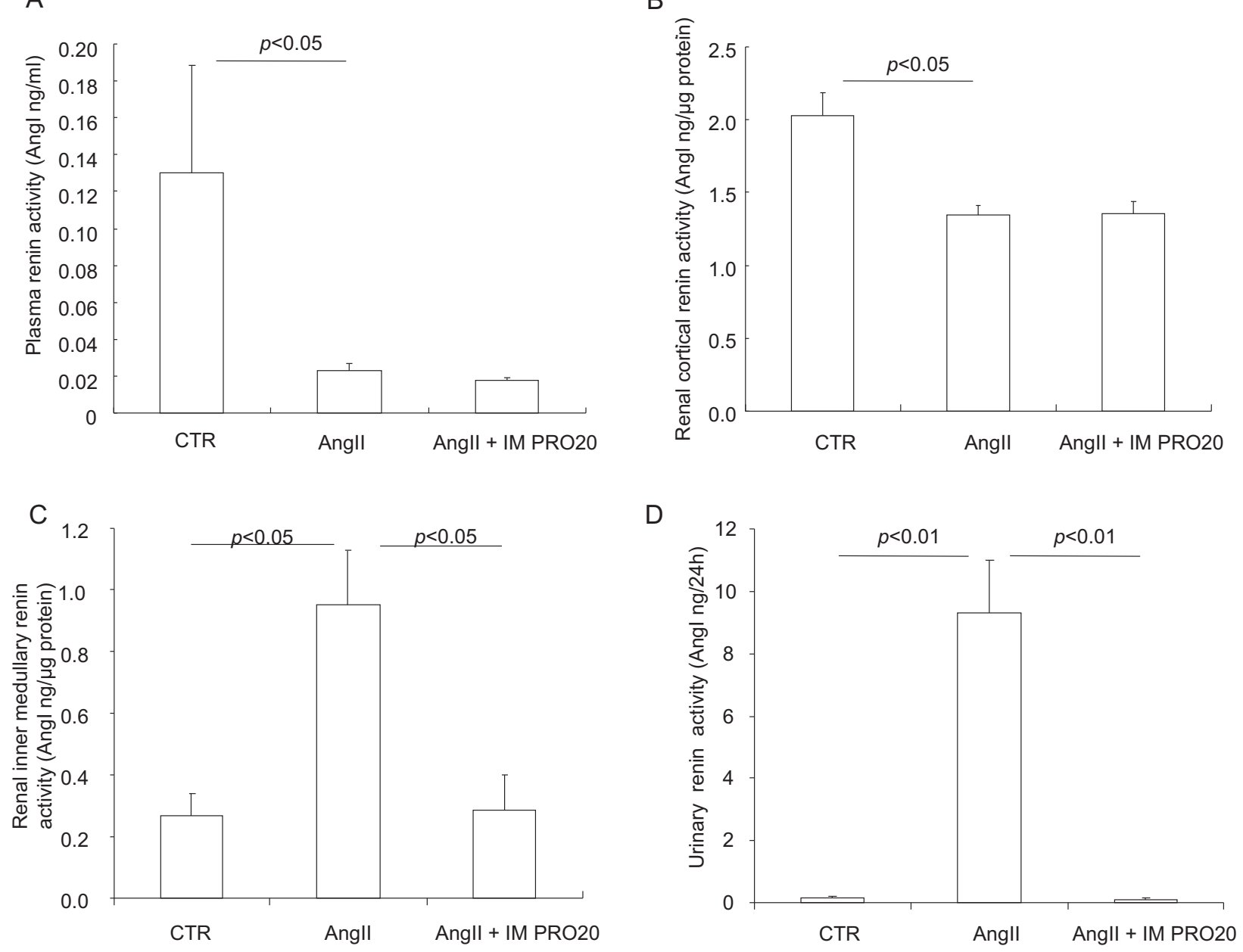

Fig. 4 Effect of intramedullary (pro)renin receptor (PRR) inhibition on renin levels in angiotensin II (Angll)-infused rats. Plasma, urine, and renal tissues from control (CTR), Angll, and Angll + intramedullary PRO20-infused (Angll + M RPO20) rats were assayed for renin activity by measurement of Angl generation. a Plasma renin activity. b Renal cortical renin activity. c Renal inner medullary renin activity. $\mathbf{d}$ Urinary renin activity. $\mathrm{N}=5-6$ per group. Data are means \pm standard error

labeling was co-localized with $\alpha$-SMA labeling (Fig. 6b). In cultured rat VSMC, exposure to $100 \mathrm{nM}$ AngII for 24 $\mathrm{h}$ induced a marked increase in medium prorenin/renin and sPRR, both being assessed by ELISA (Fig. 7a). In parallel, renin activity was increased, as reflected by measuring AngI generation, and was blunted by PRO20 (Fig. 7b).

\section{Discussion}

The importance of the RAS in the pathogenesis of human hypertension is highlighted by the wide use of ACE inhibitors and angiotensin receptor blockers as first-line antihypertensive therapies [1-3]. However, despite intensive investigation, the mechanism of AngII-induced hypertension is still incompletely understood. We used a pharmacological approach to investigate the functional role of renal medullary PRR during AngII-induced hypertension. PRO20 is a newly developed, highly specific PRR decoy inhibitor that interrupts the binding of prorenin to PRR [30]. The inhibitor was directly delivered to the rat renal medulla to evaluate the contribution of renal medullary PRR to AngII-induced hypertension. The result showed that renal delivery of PRO20 almost completely abolished AngII-induced hypertension, contrasting with a relatively modest BPlowering effect of IV PRO20. The difference in the effects of local versus systemic delivery of PRO20 reflects the contribution of renal medullary PRR.

Although abundant in vitro evidence demonstrates that PRR binds renin and prorenin to increase their catalytic activity $[8,12,31-33]$, solid in vivo evidence to support PRR as a renin regulator is still lacking. In fact, increasing skepticism has surrounded the reninregulatory function of PRR. For example, overexpression 


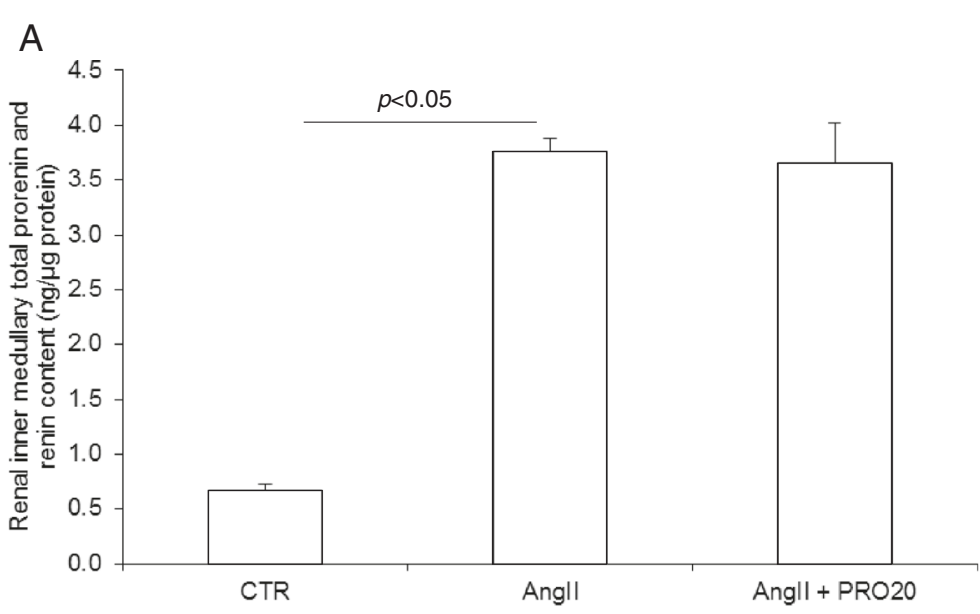

B

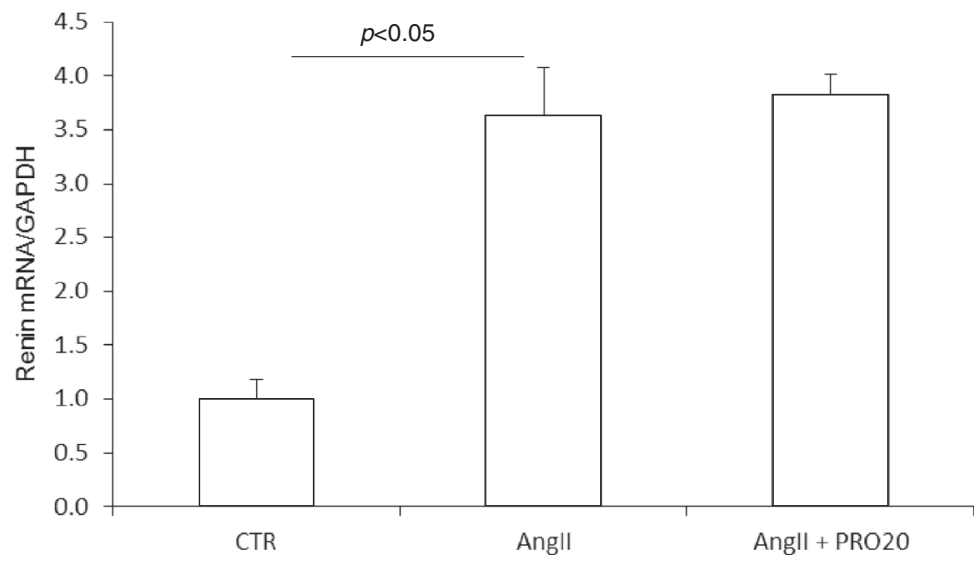

Fig. 5 Effect of intramedullary (pro)renin receptor (PRR) inhibition on renal inner medullary prorenin/renin expression in angiotensin II (Angln)infused rats. The expression of prorenin/renin in the inner medulla was determined by using enzyme-linked immunosorbent assay (ELISA) and quantitative reverse transcriptase polymerase chain reaction (qRT-PCR) determined in Control (CTR), Angll, or Angll + intramedullary PRO20-infused (Angll + M RPO20) rats. a ELISA detection of prorenin/renin content. $\mathbf{b}$ qRT-PCR detection of renin mRNA expression. $N=5-6$ per group. Data are means \pm standard error

of human PRR in rats resulted in proteinuria and nephropathy but did not elevate BP or renal AngII levels $[34,35]$. The lack of viable PRR null mice and an effective PRR inhibitor has made it difficult to convincingly prove PRR as a key player in the RAS [36]. In the present study, renal medullary and urinary renin activity was activated following AngII infusion, whereas plasma and renal cortical renin activity was suppressed, highlighting differences between systemic versus intrarenal renin systems as documented by previous studies $[16,18,27]$. AngII-induced increases in renal inner medullary and urinary renin activity were remarkably suppressed by IM PRO20. These results represent strong in vivo evidence for a role of PRR in the regulation of local renin activity during AngII-induced hypertension.

We assessed the direct role of PRR in the regulation of renin activity in cultured VSMC following AngII treatment. Exposure of VSMC to AngII induced a significant increase in medium renin activity, suggesting a positive feedback regulation of local RAS by AngII in the vasculature contrasting to the negative feedback regulation at the juxtaglomerular apparatus. This finding is in agreement with the appreciated role of the local RAS in the vascular remodeling in animal models of balloon injury [37], spontaneously hypertensive rats [38], and one-kidney, one-clip-induced and two-kidney, oneclip-induced hypertension $[39,40]$. We found that the AngII-induced local renin response in VSMC was attenuated by $\mathrm{PRO} 20$, indicating involvement of PRR. Likewise, PRR plays an important role in amplifying the vascular renin response to AngII. We suspect the PRRdependent activation of the local RAS may participate in the regulation of vascular function or remodeling during AngII-induced hypertension. This notion is in agreement 


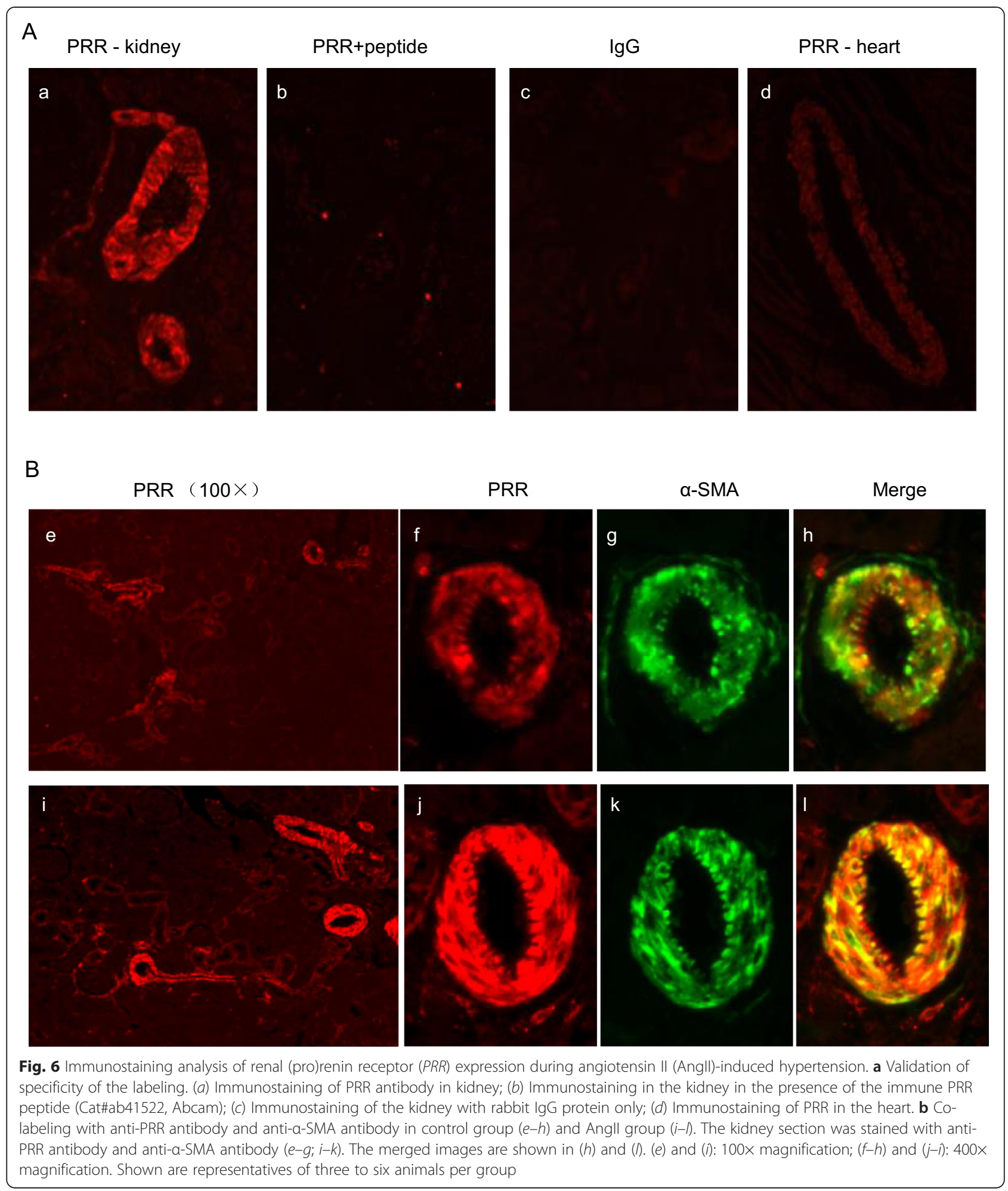

with the significant role of PRR in determining the integrity of VSMC [41]. Besides VSMC, the CD is another important site for increased renal PRR expression in this hypertension model, as shown previously $[16,18]$, and likely plays a contributory role as well. Similarly, renin secretion from the CD cells is also stimulated by AngII [27] and this stimulation is likely mediated by PRR. The relative importance of vascular versus tubular PRR 

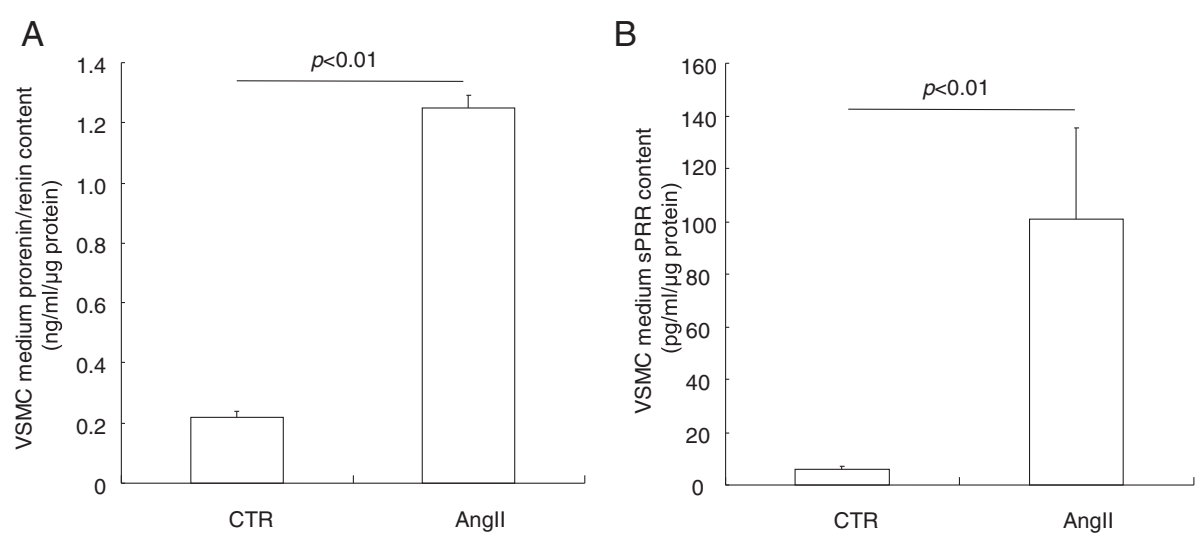

C

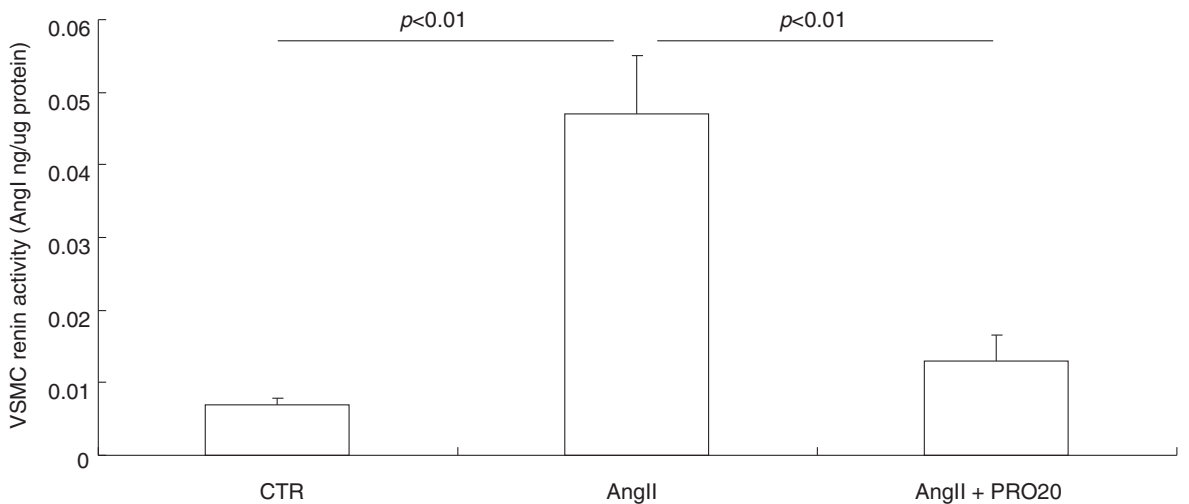

Fig. 7 Effect of angiotensin II (Angll) on prorenin/renin content, soluble (pro)renin receptor (SPRR) content and renin activity in rat vascular smooth muscle cells (VSMCS). The cells were exposed to $100 \mathrm{nM}$ Angll for $24 \mathrm{~h}$ and medium prorenin/renin content (a) and sPRR content (b) was analyzed by enzyme-linked immunosorbent assay. Medium renin activity (c) was analyzed by measurement of Angl generation in the absence of substrate. $N=12$ per group. Data are means \pm standard error. CTR control

remains elusive and awaits genetic validation in the future studies. There is an intriguing possibility that PRRdependent regulation of the local renin response may coordinate the functions of the vasculature and the $\mathrm{CD}$. Such coordination can be mediated by releasing sPRR, which acts in an autocrine or paracrine fashion.

Irrespective of the underlying mechanism, the present study has characterized PRO20 as a novel therapeutic approach for hypertension and kidney injury. However, the well-recognized developmental role of PRR may imply a safety concern with this approach. In both low vertebrates and mammals, PRR plays an essential role in embryogenesis, likely via activation of the $\mathrm{Wnt} / \mathrm{\beta}$-catenin pathway $[15,36]$. In particular, deletion of PRR in mice in a conventional or conditional manner leads to a lethal phenotype $[36,42]$. However, to our surprise, there was no noticeable toxicity associated with PRO20 in the current experimental model. In agreement with this observation, inhibition of the Wnt/ $\beta$-catenin pathway exhibits antifibrotic and protective effects in animal models of diverse fibrotic diseases in the kidney [43-45], skin [46], and lung [47] with a generally optimal safety profile. It is possible that the developmental pathway may be selectively activated in some disease processes and may represent an attractive therapeutic target.

\section{Conclusion}

The present study employed a newly developed PRRdecoy peptide, PRO20, coupled with an intramedullary infusion technique to investigate the functional role of renal medullary PRR during AngII-induced hypertension. Not only did we demonstrate a remarkable BPlowering effect of intramedullary PRR antagonism, but we also underscored a novel mechanism of this phenomenon involving PRR-dependent activation of the local renin response. We for the first time demonstrate the renin regulatory function of PRR in vivo and in vitro and report $\mathrm{PRO} 20$ as a novel therapeutic agent for hypertension and chronic kidney disease.

\section{Abbreviations}

ACE: angiotensin-converting enzyme; Angll: angiotensin II; BP: blood pressure; CD: collecting duct; ELISA: enzyme-linked immunosorbent assay; IM 
PRO20: intramedullary PRO20 infusion; IV PRO20: intravenous PRO20 infusion; MAP: mean arterial pressure; PRR: (pro)renin receptor; qRT-PCR: quantitative reverse transcriptase polymerase chain reaction; RAS: renin-angiotensin system; sPRR: soluble form of PRR; VSMC: vascular smooth muscle cells.

\section{Competing interests}

The authors declare that they have no competing interests.

\section{Authors' contributions}

FW, XHL, and TXY designed the research; FW, XHL, and ML performed the experiments; FW, XHL, ML, and TXY analyzed the data; FW, XHL, ML, YMF, SFZ, and TXY interpreted results of the experiments; FW, XHL, and TXY prepared the figures; FW, XHL, and TXY drafted the manuscript; FW, XHL, and TXY edited and revised the manuscript; FW, XHL, ML, YMF, SFZ, and TXY read and approved the final version of the manuscript.

\section{Acknowledgements}

This work was supported by National Natural Science Foundation of China Grant No. 91439205 and No. 31330037, National Institutes of Health Grants DK104072 and DK094956, National Basic Research Program of China 973 Program 2012 CB517600 (No. 2012CB517602), and VA Merit Review from Department of Veterans Affairs. TXY is a Research Career Scientist in the Department of Veterans Affairs.

\section{Author details}

${ }^{1}$ Institute of Hypertension, Sun Yat-sen University School of Medicine, \#74 Zhongshan 2nd Road, Science and Technology Building, 6th Floor, Guangzhou 510080, P. R. China. ${ }^{2}$ Internal Medicine, University of Utah and Veterans Affairs Medical Center, Salt Lake City, UT, USA. ${ }^{3}$ Departments of Pharmacology and Physiology \& Cell Biology, University of Nevada School of Medicine, Reno, NE, USA. ${ }^{4}$ Department of Pharmaceutical Sciences, College of Pharmacy, University of South Florida, Tampa, FL, USA.

\section{Received: 28 August 2015 Accepted: 14 October 2015} Published online: 10 November 2015

\section{References}

1. Hansson L, Lindholm LH, Niskanen L, Lanke J, Hedner T, Niklason A, et al. Effect of angiotensin-converting-enzyme inhibition compared with conventional therapy on cardiovascular morbidity and mortality in hypertension: the Captopril Prevention Project (CAPPP) randomised trial. Lancet. 1999;353(9153):611-6.

2. Dahlof B, Devereux RB, Kjeldsen SE, Julius S, Beevers G, de Faire U, et al. Cardiovascular morbidity and mortality in the Losartan Intervention For Endpoint reduction in hypertension study (LIFE): a randomised trial against atenolol. Lancet. 2002;359(9311):995-1003.

3. Yusuf S, Sleight P, Pogue J, Bosch J, Davies R, Dagenais G. Effects of an angiotensin-converting-enzyme inhibitor, ramipril, on cardiovascular events in high-risk patients. The Heart Outcomes Prevention Evaluation Study Investigators. N Engl J Med. 2000;342(3):145-53.

4. Lonn EM, Yusuf S, Jha P, Montague TJ, Teo KK, Benedict CR, et al. Emerging role of angiotensin-converting enzyme inhibitors in cardiac and vascular protection. Circulation. 1994;90(4):2056-69.

5. Facemire CS, Griffiths R, Audoly LP, Koller BH, Coffman TM. The impact of microsomal prostaglandin e synthase 1 on blood pressure is determined by genetic background. Hypertension. 2010;55(2):531-8.

6. Navar LG, Kobori H, Prieto MC, Gonzalez-Villalobos RA. Intratubular reninangiotensin system in hypertension. Hypertension. 2011;57(3):355-62.

7. Navar LG, Harrison-Bernard LM, Nishiyama A, Kobori H. Regulation of intrarenal angiotensin II in hypertension. Hypertension. 2002;39(2 Pt 2):316-22

8. Nguyen G, Delarue F, Burckle C, Bouzhir L, Giller T, Sraer JD. Pivotal role of the renin/prorenin receptor in angiotensin II production and cellular responses to renin. J Clin Invest. 2002;109(11):1417-27.

9. Burckle C, Bader M. Prorenin and its ancient receptor. Hypertension. 2006:48(4):549-51.

10. Cousin C, Bracquart D, Contrepas A, Corvol P, Muller L, Nguyen G. Soluble form of the (pro)renin receptor generated by intracellular cleavage by furin is secreted in plasma. Hypertension. 2009;53(6):1077-82.

11. Ludwig J, Kerscher S, Brandt U, Pfeiffer K, Getlawi F, Apps DK, et al. Identification and characterization of a novel 9.2-kDa membrane sector- associated protein of vacuolar proton-ATPase from chromaffin granules. J Biol Chem. 1998;273(18):10939-47.

12. Nabi AH, Kageshima A, Uddin MN, Nakagawa T, Park EY, Suzuki F. Binding properties of rat prorenin and renin to the recombinant rat renin/prorenin receptor prepared by a baculovirus expression system. Int J Mol Med. 2006;18(3):483-8.

13. Achard V, Boullu-Ciocca S, Desbriere R, Nguyen G, Grino M. Renin receptor expression in human adipose tissue. Am J Physiol Regul Integr Comp Physiol. 2007;292(1):R274-82.

14. Saris JJ, t Hoen PA, Garrelds IM, Dekkers DH, den Dunnen JT, Lamers JM, et al. Prorenin induces intracellular signaling in cardiomyocytes independently of angiotensin II. Hypertension. 2006;48(4):564-71.

15. Cruciat CM, Ohkawara B, Acebron SP, Karaulanov E, Reinhard C, Ingelfinger $\mathrm{D}$, et al. Requirement of prorenin receptor and vacuolar H +-ATPasemediated acidification for Wnt signaling. Science. 2010;327(5964):459-63.

16. Wang F, Lu X, Peng K, Du Y, Zhou SF, Zhang A, et al. Prostaglandin e-prostanoid4 receptor mediates angiotensin II-induced (pro)renin receptor expression in the rat renal medulla. Hypertension. 2014;64:369-77.

17. Advani A, Kelly DJ, Cox AJ, White KE, Advani SL, Thai K, et al. The (Pro)renin receptor: site-specific and functional linkage to the vacuolar $\mathrm{H}+-$ ATPase in the kidney. Hypertension. 2009;54(2):261-9.

18. Wang F, Lu X, Peng K, Zhou L, Li C, Wang W, et al. COX-2 Mediates angiotensin II-induced (pro)renin receptor expression in the rat renal medulla. Am J Physiol Renal Physiol. 2014;307:F25-32.

19. Gonzalez AA, Lara LS, Luffman C, Seth DM, Prieto MC. Soluble form of the (pro)renin receptor is augmented in the collecting duct and urine of chronic angiotensin II-dependent hypertensive rats. Hypertension. 2011;57(4):859-64.

20. Gonzalez AA, Green T, Luffman C, Bourgeois CR, Gabriel Navar L, Prieto MC Renal medullary cyclooxygenase-2 and (pro)renin receptor expression during angiotensin II-dependent hypertension. Am J Physiol Renal Physiol. 2014;307(8):F962-70.

21. Yang T, Huang YG, Ye W, Hansen P, Schnermann JB, Briggs JP. Influence of genetic background and gender on hypertension and renal failure in COX-2-deficient mice. Am J Physiol Renal Physiol. 2005;288(6):F1125-32.

22. Paliege A, Mizel D, Medina C, Pasumarthy A, Huang YG, Bachmann S, et al. Inhibition of nNOS expression in the macula densa by COX-2-derived prostaglandin E(2). Am J Physiol Renal Physiol. 2004;287(1):F152-9.

23. Li W, Sullivan MN, Zhang S, Worker CJ, Xiong Z, Speth RC, et al. Intracerebroventricular infusion of the (Pro)renin receptor antagonist PRO20 attenuates deoxycorticosterone acetate-salt-induced hypertension. Hypertension. 2015;65(2):352-61.

24. Miyata N, Cowley Jr AW. Renal intramedullary infusion of L-arginine prevents reduction of medullary blood flow and hypertension in Dahl salt-sensitive rats. Hypertension. 1999;33(1 Pt 2):446-50.

25. Zhang L, Cheng J, Ma Y, Thomas W, Zhang J, Du J. Dual pathways for nuclear factor kappaB activation by angiotensin II in vascular smooth muscle: phosphorylation of p65 by lkappaB kinase and ribosomal kinase. Circ Res. 2005;97(10):975-82.

26. Liu Z, Morgan S, Ren J, Wang Q, Annis DS, Mosher DF, et al. Thrombospondin-1 (TSP1) contributes to the development of vascular inflammation by regulating monocytic cell motility in mouse models of abdominal aortic aneurysm. Circ Res. 2015;117(2):129-41.

27. Gonzalez AA, Liu L, Lara LS, Seth DM, Navar LG, Prieto MC. Angiotensin ॥ stimulates renin in inner medullary collecting duct cells via protein kinase $C$ and independent of epithelial sodium channel and mineralocorticoid receptor activity. Hypertension. 2011;57(3):594-9.

28. Prieto-Carrasquero MC, Harrison-Bernard LM, Kobori H, Ozawa Y, HeringSmith KS, Hamm LL, et al. Enhancement of collecting duct renin in angiotensin II-dependent hypertensive rats. Hypertension. 2004;44(2):223-9.

29. Prieto-Carrasquero MC, Kobori H, Ozawa Y, Gutierrez A, Seth D, Navar LG. AT1 receptor-mediated enhancement of collecting duct renin in angiotensin II-dependent hypertensive rats. Am J Physiol Renal Physiol. 2005;289(3):F632-7.

30. Li W, Sullivan MN, Zhang S, Worker CJ, Xiong Z, Speth RC, et al. Intracerebroventricular infusion of the (pro)renin receptor antagonist pro20 attenuates deoxycorticosterone acetate-salt-induced hypertension. Hypertension. 2014;65:352-61.

31. Batenburg WW, Krop M, Garrelds IM, de Vries R, de Bruin RJ, Burckle CA, et al. Prorenin is the endogenous agonist of the (pro)renin receptor. Binding kinetics of renin and prorenin in rat vascular smooth muscle cells 
overexpressing the human (pro)renin receptor. J Hypertens. 2007;25(12):2441-53.

32. Batenburg WW, de Bruin RJ, van Gool JM, Muller DN, Bader M, Nguyen G, et al. Aliskiren-binding increases the half life of renin and prorenin in rat aortic vascular smooth muscle cells. Arterioscler Thromb Vasc Biol. 2008;28(6):1151-7.

33. Nabi AH, Biswas KB, Nakagawa T, Ichihara A, Inagami T, Suzuki F. Prorenin has high affinity multiple binding sites for (pro)renin receptor. Biochim Biophys Acta. 2009;1794(12):1838-47.

34. Kaneshiro Y, Ichihara A, Sakoda M, Takemitsu T, Nabi AH, Uddin MN, et al. Slowly progressive, angiotensin II-independent glomerulosclerosis in human (pro)renin receptor-transgenic rats. J Am Soc Nephrol. 2007;18(6):1789-95.

35. Kaneshiro Y, Ichihara A, Takemitsu T, Sakoda M, Suzuki F, Nakagawa T, et al. Increased expression of cyclooxygenase-2 in the renal cortex of human prorenin receptor gene-transgenic rats. Kidney Int. 2006;70(4):641-6.

36. Nguyen G. Renin and prorenin receptor in hypertension: what's new? Curr Hypertens Rep. 2011;13(1):79-85.

37. Powell JS, Clozel JP, Muller RK, Kuhn H, Hefti F, Hosang M, et al. Inhibitors of angiotensin-converting enzyme prevent myointimal proliferation after vascular injury. Science. 1989;245(4914):186-8.

38. Clozel JP, Kuhn H, Hefti F. Decreases of vascular hypertrophy in four different types of arteries in spontaneously hypertensive rats. Am J Med. 1989:87(6B):92S-5.

39. Wang DH, Prewitt RL. Captopril reduces aortic and microvascular growth in hypertensive and normotensive rats. Hypertension. 1990;15(1):68-77.

40. Levy BI, Michel JB, Salzmann JL, Azizi M, Poitevin P, Safar M, et al. Effects of chronic inhibition of converting enzyme on mechanical and structural properties of arteries in rat renovascular hypertension. Circ Res. 1988;63(1):227-39.

41. Kurauchi-Mito A, Ichihara A, Bokuda K, Sakoda M, Kinouchi K, Yaguchi T, et al. Significant roles of the (pro)renin receptor in integrity of vascular smooth muscle cells. Hypertens Res. 2014;37(9):830-5.

42. Rousselle A, Sihn G, Rotteveel M, Bader M. (Pro)renin receptor and V-ATPase: from Drosophila to humans. Clin Sci (Lond). 2014;126(8):529-36.

43. Hao S, He W, Li Y, Ding H, Hou Y, Nie J, et al. Targeted inhibition of betacatenin/CBP signaling ameliorates renal interstitial fibrosis. J Am Soc Nephrol. 2011;22(9):1642-53.

44. Zhou B, Liu Y, Kahn M, Ann DK, Han A, Wang H, et al. Interactions between beta-catenin and transforming growth factor-beta signaling pathways mediate epithelial-mesenchymal transition and are dependent on the transcriptional co-activator CAMP-response element-binding protein (CREB)binding protein (CBP). J Biol Chem. 2012;287(10):7026-38.

45. Zhou L, Li Y, Hao S, Zhou D, Tan RJ, Nie J, et al. Multiple genes of the reninangiotensin system are novel targets of Wnt/beta-catenin signaling. J Am Soc Nephrol. 2015;26(1):107-20.

46. Beyer C, Reichert H, Akan H, Mallano T, Schramm A, Dees C, et al. Blockade of canonical Wnt signalling ameliorates experimental dermal fibrosis. Ann Rheum Dis. 2013;72(7):1255-8.

47. Henderson Jr WR, Chi EY, Ye X, Nguyen C, Tien YT, Zhou B, et al. Inhibition of Wnt/beta-catenin/CREB binding protein (CBP) signaling reverses pulmonary fibrosis. Proc Natl Acad Sci U S A. 2010;107(32):14309-14.

\section{Submit your next manuscript to BioMed Central and take full advantage of:}

- Convenient online submission

- Thorough peer review

- No space constraints or color figure charges

- Immediate publication on acceptance

- Inclusion in PubMed, CAS, Scopus and Google Scholar

- Research which is freely available for redistribution 